\title{
Developing services for a public health approach to child maltreatment
}

\author{
Ruth Gilbert, Jenny Woodman \& Stuart Logan* \\ a) Professor of Clinical Epidemiology, MRC Centre of Epidemiology for Child Health, \\ UCL Institute of Child Health, London \\ r.gilbert@ucl.ac.uk \\ b) PhD student, MRC Centre of Epidemiology for Child Health, \\ UCL Institute of Child Health, London \\ j.woodman@ucl.ac.uk \\ c) Professor of Paediatric Epidemiology, Director, Institute of Health Services Research, \\ Peninsula Medical School, Exeter \\ Stuart.logan@pms.ac.uk
}

\begin{abstract}
Calls for a public health approach to child maltreatment - a strategy that aims primarily to reduce risk factors for maltreatment - have been based on four main arguments. (O'Donnell et al. 2008; Reading et al. 2009; Barlow and Calam, 2011) The right of children to be protected from harm in the first place. The frequency of child maltreatment, which, if all occurrences were notified, would overwhelm child protection systems. The inaccuracy of identification systems, which miss the large majority of maltreated children. And fourth, the effectiveness and cost effectiveness of intervening to prevent child maltreatment comparing with intervention once child maltreatment has occurred. We review the evidence to support these arguments and trace the development of UK policy and health services towards a public health approach.
\end{abstract}

Keywords

child protection; child maltreatment; child abuse; neglect; policy; services

\section{Definitions}

\section{Public Health approach}

A public health approach defines a four-step process. Defining the condition in the population, determining the risk factors for the condition, developing interventions to address the risk factors and thereby reduce the frequency of the condition, and lastly implementing and monitoring the effectiveness of the intervention on a population basis. (Violence Prevention Alliance, 2011)

\footnotetext{
*) We are grateful to Danya Glaser and June Thoburn for commenting on a draft of this report.
} 
For child maltreatment, a public health approach means focusing on reducing the risk factors that give rise to maltreatment, rather than on maltreatment once it has occurred. A public health approach therefore translates as a preventive approach, which can act on risk factors at all levels of the ecological model of maltreatment:(Sidebotham, 2001) whole society, neighbourhood, family, parent and child. Depending on the risk factors being addressed, preventive interventions may be universal (e.g.: legislation), or targeted (e.g.: parent training). A further distinction commonly used in public health is between primary prevention, preventing occurrence of the condition in the first place, and secondary prevention, preventing recurrence once the condition has occurred. This distinction is less useful in the field of child maltreatment as, by its nature, maltreatment is often hidden. Hence, primary prevention may be used for children who have already been maltreated.

\section{Child maltreatment}

Child maltreatment is defined by any acts of commission or omission by a parent or other caregiver that result in harm, potential for harm, or threat of harm to a child, even if harm is not the intended consequence. (Leeb et al. 2008; Department for Education, 2010) Four forms of maltreatment are widely recognised - physical abuse, sexual abuse, emotional abuse, and neglect - which frequently co-exist. Increasingly, witnessing intimate partner violence is also regarded as a form of child maltreatment. Neglect and emotional abuse, are by definition, persistent problems, manifest by harmful parent-child interactions, whereas physical and sexual abuse and witnessing intimate partner violence are events, which may be covert. (Gilbert et al. 2009b) $80 \%$ or more of maltreatment is perpetrated by parents or parent substitutes, apart from sexual abuse, which is most frequently perpetrated by acquaintances or other relatives. (Gilbert et al. 2009b)

\section{Frequency of child maltreatment and risk factors}

Broad agreement across rich and middle income countries on what constitutes child maltreatment has paved the way for improved tools for measuring its occurrence. Since the 199os, validated self-report or parent-report survey tools have emerged as an alternative to child protection agency information for measuring child maltreatment. (Andrews et al. 2004; Sebre et al. 2004; Zolotor et al. 2009; Gray, 2010; Runyan et al. 2010; Unicef, 2010; Runyan and Zolotor, 2011) These surveys have highlighted the fact that child maltreatment is common: between 1 in 25 to 1 in 10 children are exposed each year in the UK. (Gilbert et al. 2009b; Finkelhor et al. 2010; Radford et al. 2011) This is far more 
children than are receiving child protection services at any one time. Approximately $3.5 \%$ of children each year are classified as a child in need and receive social care services and 4 per 1000 are on a child protection plan in England - mainly for neglect or emotional abuse. (Department for Education, 2011a) Which children receive 'in need' services or a child protection plan is highly variable. Such decisions on who needs services or protection also appear to be relatively inaccurate as they correlate poorly with the risk of recurrence of maltreatment, (Gilbert et al. 2009a; Barlow and Calam, 2011) or with other markers of child maltreatment. (Gilbert et al. 2012) Data from protection agency activity are therefore poor indicators of actual maltreatment. Agency activity is driven more by capacity and policy directives than by actual occurrence of maltreatment. (Gilbert et al. 2009a)

Self-report and parent-report studies have also advanced our understanding of the type of children affected by maltreatment. We now know that, far from being a problem that mainly affects young children, child maltreatment is highly prevalent in adolescents. (Finkelhor et al. 2009; Rees et al. 2010; Radford et al. 2011) We also know that children exposed to one type of maltreatment are often exposed to other types over time. Moreover, the same children are frequently exposed to other forms of victimisation - such as violence, bullying or sexual abuse - by peers or strangers - which can be just as harmful. (Turner et al. 2010a; Turner et al. 2010b) Further advances in our understanding of child maltreatment come from long-term follow up studies of maltreated children. These have shown that child maltreatment (whether reported to agencies or self-reported) is often a chronic condition with long term consequences, such as increased risks of poor mental health, obesity or alcohol abuse, and involvement in violence and criminality, that persist into middle age. (Gilbert et al. 20ogb)

Numerous, population-based studies provide clear evidence about the environmental, parent and child risk factors. (Gilbert et al. 2009b) Poverty, unemployment, poor housing and a lack of social support are all related to an increased risk of maltreatment. Parent risk factors include mental health problems, drug and alcohol misuse, intimate partner violence and parents' own exposure to maltreatment or their lack of experience of positive parenting in childhood, all increase the risk of inadequate or abusive parenting. Child risk factors include disability and chronic disease. Behaviour problems in children can be both risk factors and consequences of maltreatment. These risk factors often coexist and interact adding stresses and demands on parents who may already have limited parenting capacity, family support and financial resources. It is easy to understand how this combination of adversity for the parents and child can lead to some children experiencing episodes of maltreatment or chronic failure of adequate parenting manifested as neglect or emotional abuse. 
Major consequences flow from this population-based view of child maltreatment and its risk factors. The first is the fact that child maltreatment involves a range of severity that reaches far into the 'normal' population. Maltreatment is not inflicted only by unimaginably vicious or neglectful parents but occurs as part of a spectrum of parenting behaviour ranging from optimal to severely abusive (figure 1 ).

The second consequence is the realisation that most maltreated children do not come to the attention of child protection agencies most of the time. Numerous studies have shown that professionals (including paediatricians) refer to child protection services only a minority of the children whom they suspect of being maltreated. (Gilbert et al. 2009a) Reasons include uncertainty about the diagnosis, lack of confidence that referral will do more good than harm, and concerns about the capacity of services to respond. Even when children are investigated and followed up by child protection agencies because of child maltreatment, such input is usually short-term (e.g. child protection plans last a year on average). (Department for Education, 2011a) Most children remain with their family, where interventions to reduce recurrence of maltreatment may not be effective or may not even be offered. The implication is that even children with confirmed maltreatment spend most of their childhood outside the scrutiny of formally designated child protection services.

Third, to address the widespread occurrence of maltreatment, strategies need to shift from an emphasis on immediate child safety and forensic assessment to determine culpability, to a public health approach focussed on reducing risk factors.

Fourth, along with the focus on a public health, preventative approach there has been growing use of robust methods, such as randomised controlled trials, to evaluate the effectiveness of these interventions for child maltreatment. (MacMillan et al. 2009a) These evaluations have found that few in-home interventions are effective for preventing recurrence of maltreatment, especially not for neglect. Much less evidence exists for interventions to prevent recurrence of maltreatment after it has occurred. For example, there have been no randomised controlled trials comparing out-of-home with in-home care on the child's safety, health, achievements, and quality of life. The most striking finding is how few randomised controlled trials have been done, despite the harms and costs associated with child maltreatment. (Barth, 2009; MacMillan et al. 2009a) Although patchy, the available evidence suggests that targeted interventions to prevent maltreatment are likely to be more effective and cost effective than child protection once maltreatment has occurred. (O'Donnell et al. 2008; Stagner and Lansing, 2009; Flaherty and Stirling, 2010; Munro, 2011) The need for this shift in emphasis was advocated in the 1963 Children and Young Persons Act, reiterated in the Children Act 1989 and in research in the 1990s, and again recently in the Munro report (figure 1 and table 1). (Munro, 


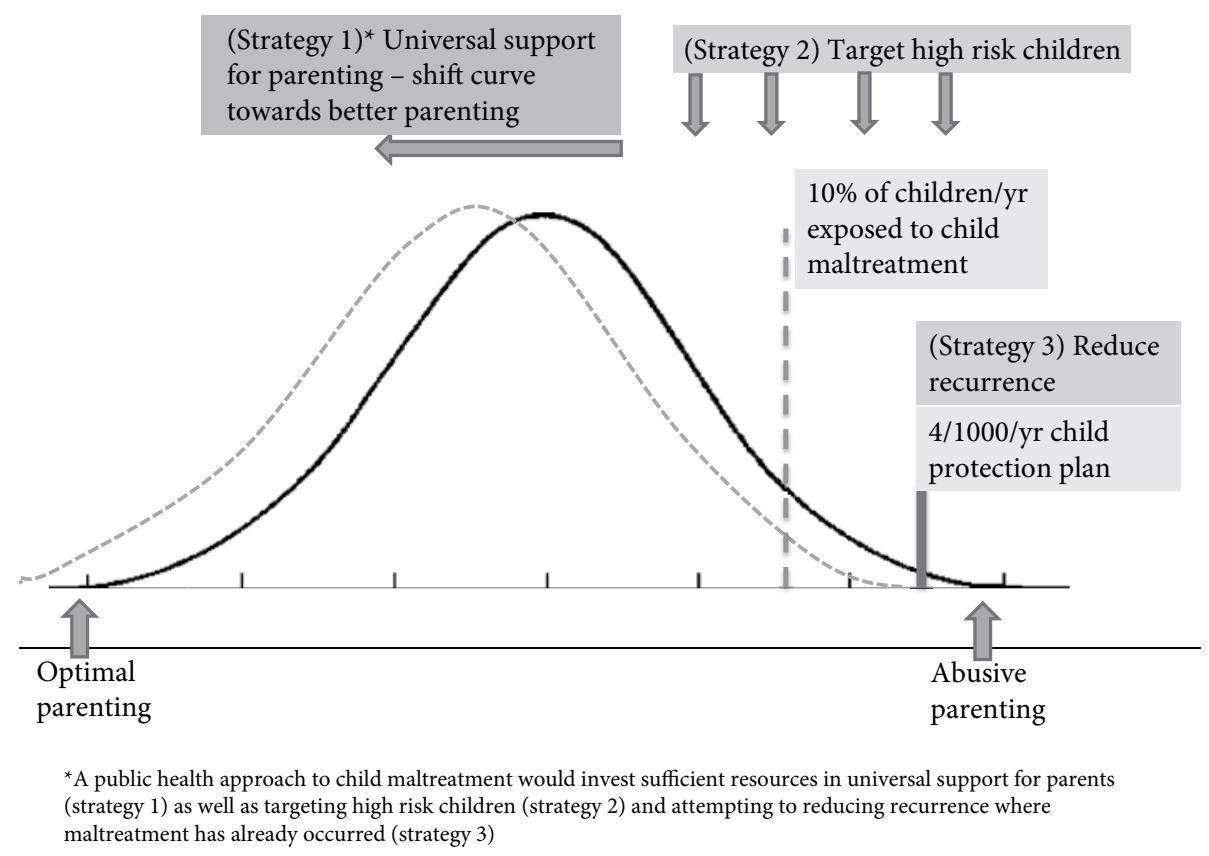

Figure 1 Distribution from optimal to abusive parenting and representation of policy to reduce child maltreatment.

2011) A preventive approach to child maltreatment is slowly gaining momentum, but effective translation into practice has been patchy.

We discuss the faltering development of a preventive approach in healthcare and children's social care services. Education services are also critical to the prevention, as well as recognition and response to child maltreatment, but their role is beyond this paper.

\section{Preventive policies}

The curve in figure 1 represents a simplified view of parenting from optimal, which few of us achieve, through to harmful, abusive parenting. Leaving aside arguments about how parenting (on the $\mathrm{x}$ axis) could be measured and whether it would be symmetrically distributed, the diagram can help to explain the theoretical impact of a public health approach to improve parenting. The theory states that universal, whole population strategies for improving levels of parenting, would shift the curve to the left. (Rose et al. 2008) This could improve parent-child interaction a small amount on average for the whole population, potentially impacting on behaviour, depression, self-esteem, school achievement, obesity, and other outcomes related to less than optimal 
Table 1 Children's social care policy timeline

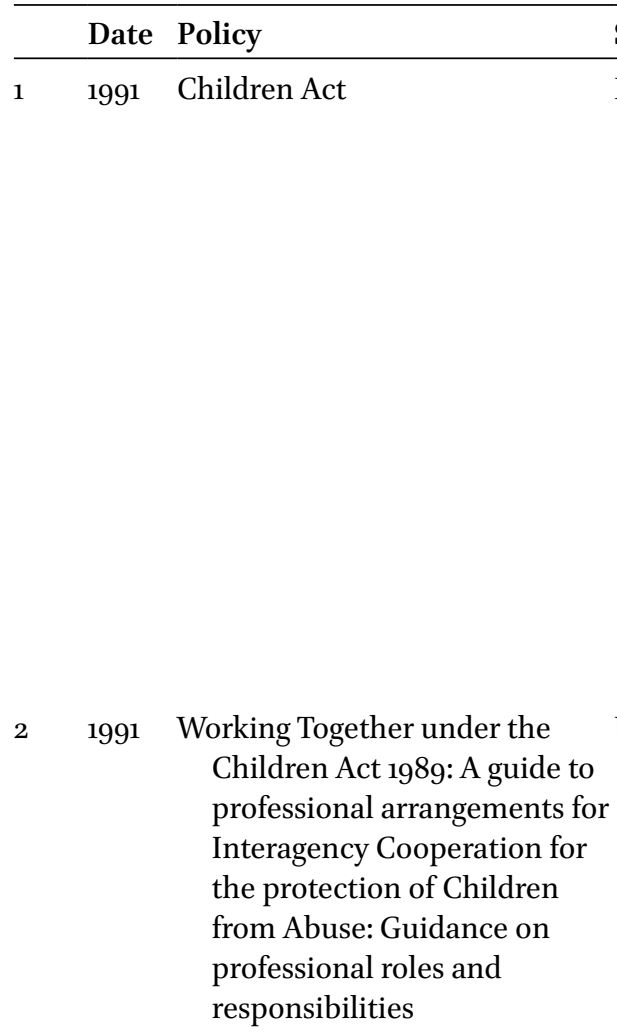

Significance

Emphasised balance between protecting children from abuse and protecting families from unnecessary and unwarranted intrusion by the state. Introduced concept of 'likely' significant harm as threshold for statutory action by local authorities to protect children from abuse (section 47). Set out statutory duty for local authorities to provide services to children 'in need' and their families (section 17). Created statutory responsibility for all professionals to refer concerns about child abuse and neglect to an agency with power to investigate and intervene (social services, police or NSPCC).

Update of 1988 'Working Together'. Focused on identifying children likely to suffer significant harm and how and when to carry out a investigation (section 47 Children Act). Part 8 contained expanded guidance on 'case reviews' (now know as 'serious case reviews'), first introduced in the 1988 Working Together.

1999 Working Together to safeguarding children: A guide to Inter-agency Working to safeguarding and Promote the Welfare of Children of Children in Need and their Families

Update of 1991 'Working Together'. Focus broadened from child protection (section 47 Children Act) to also include safeguarding and promoting children's welfare (section 17 Children Act). Published in the context of the 'refocussing debate' which emphasis the importance of family support services for children in need, alongside child protection services for those likely to suffer significant harm.

Primarily a practice tool for professionals, which was designed to help determine whether a child was in need or likely to suffer significant harm and to determine appropriate family support services. 
Table 1 (Cont.)

\begin{tabular}{|c|c|c|c|}
\hline & Date & Policy & Significance \\
\hline 5 & 2000 & Protection of Children List & $\begin{array}{l}\text { The Protection of Children Act (1999) } \\
\text { required recording of individuals } \\
\text { disqualified from working with children. }\end{array}$ \\
\hline 6 & 2002 & National Service Framework & $\begin{array}{l}\text { Aimed to establish clear standards for } \\
\text { promoting the health and well-being of } \\
\text { children and young people and for } \\
\text { providing high quality services which } \\
\text { meet their needs. Set child protection } \\
\text { services in the wider context of services } \\
\text { to safeguarding children and promote } \\
\text { child welfare }\end{array}$ \\
\hline 7 & 2003 & $\begin{array}{l}\text { Every Child Matters: Change } \\
\text { for Children }\end{array}$ & $\begin{array}{l}\text { The ambitious Every Child Matters agenda } \\
\text { was framed in terms of supporting all } \\
\text { children. It conceptualised children on } \\
\text { a spectrum, ranging from those needing } \\
\text { only universal services to those needing } \\
\text { specialist services, such as child protec- } \\
\text { tion. The programme aimed to intergrate } \\
\text { universal, targetted and specialist } \\
\text { services so that child protection and } \\
\text { safeguarding were not isolated from } \\
\text { services to meet the needs of all families. } \\
\text { The guidance aimed to promote } \\
\text { prevention whilst also strengthening } \\
\text { protection. }\end{array}$ \\
\hline 8 & 2004 & Children Act & $\begin{array}{l}\text { The updated Children Act placed " a duty to } \\
\text { cooperate" on all services and required } \\
\text { all local authorities to replace Area Child } \\
\text { Protection Committees with Local } \\
\text { Safeguarding Children Boards. It also } \\
\text { created a statutory duty for agencies, } \\
\text { including health, to make sure they had } \\
\text { made arrangements to safeguard and } \\
\text { promote the welfare of children. }\end{array}$ \\
\hline 9 & 2006 & $\begin{array}{l}\text { Working Together to } \\
\text { safeguarding children: } \\
\text { A guide to Inter-agency } \\
\text { Working to safeguarding } \\
\text { and Promote the Welfare } \\
\text { of Children }\end{array}$ & $\begin{array}{l}\text { The Working Together guidance revisd in } \\
\text { repsonse to the public inquiry report by } \\
\text { Lord Laming into the high profile death } \\
\text { of Victoria Climbie as a result of } \\
\text { maltreatment from her carers. It offered } \\
\text { the first detailed definition of 'safeguard- } \\
\text { ing' and supported the Every Child } \\
\text { matters agenda. }\end{array}$ \\
\hline
\end{tabular}

(Continued) 
Table 1 (Cont.)

\begin{tabular}{|c|c|c|c|}
\hline & Date & Policy & Significance \\
\hline 10 & 2009 & $\begin{array}{l}\text { NICE guidelines: When to } \\
\text { Suspect Child Maltreatment }\end{array}$ & $\begin{array}{l}\text { Evidence-based guidance for health } \\
\text { professionals on recognising and } \\
\text { responding to child maltreatment. } \\
\text { Guidance is given on the characteristics } \\
\text { and feastures which should prompt } \\
\text { professionals to 'suspect' maltreatment } \\
\text { and 'consider' maltreatment. 'Suspected' } \\
\text { abuse, with high levels of certainty and } \\
\text { severity, should be referred to social care. } \\
\text { Actions following 'considered' maltreat- } \\
\text { ment, where severity or certainty is not } \\
\text { high enough to reach thresholds for } \\
\text { social care referral but maltreatment } \\
\text { cannot be rulled out, was outside the } \\
\text { scope of the guidelines. However, NICE } \\
\text { recommends discussion with colleagues, } \\
\text { information sharing and further } \\
\text { examination. }\end{array}$ \\
\hline 11 & 2010 & $\begin{array}{l}\text { Working Together to } \\
\text { safeguarding children: } \\
\text { A guide to Inter-agency } \\
\text { Working to safeguarding } \\
\text { and Promote the Welfare } \\
\text { of Children }\end{array}$ & $\begin{array}{l}\text { The revised guidance was a response to } \\
\text { The Laming Report 20o9 'The Protection } \\
\text { of Children in England: A progress } \\
\text { Report'; a report on the implementation } \\
\text { of Laming's previous recommendations } \\
\text { following high profile cases of child } \\
\text { death from maltreatment, including } \\
\text { that of Peter Connolly. Includes further } \\
\text { detail on children who may be } \\
\text { particularly vulnerable and need } \\
\text { safeguarding and incorporates changes } \\
\text { to 'Serious case reviews' recommended } \\
\text { by Lord Laming (20og). Includes } \\
\text { interactive web-based version. }\end{array}$ \\
\hline 12 & 2011 & $\begin{array}{l}\text { The Munro review of child } \\
\text { protection: final report - a } \\
\text { child-centred system }\end{array}$ & $\begin{array}{l}\text { This Munro review was commissioned by } \\
\text { the new coalition government in 2010. It } \\
\text { calls for greater emphasis on professional } \\
\text { judgement and less target-driven, } \\
\text { protocolised activity in social care. The } \\
\text { report, and particularly the government's } \\
\text { response, acknowledge the role of } \\
\text { healthcare professionals in managing } \\
\text { children who are below the threshold for } \\
\text { referral to social care for child protection } \\
\text { but details are lacking on how this role } \\
\text { should be implemented and supported. }\end{array}$ \\
\hline
\end{tabular}


parenting. A small shift for the population overall, would also shift many of those in tail of the distribution on the right, out of abusive parenting (figure 1).

Examples of whole-population, universal strategies likely to shift parenting include legislation against smacking, reducing child poverty, and improving support for parents. Empirical evidence of the effectiveness of these approaches is difficult to obtain. The best example comes from Sweden, where repeated self-report and parent-report studies over four decades have shown a decline in the reported prevalence of physical abuse. (Gilbert et al. 20ogb) Pinpointing which interventions caused these changes is very difficult. In practice, multiple factors are likely to have contributed. Much of the decline predated legislation banning smacking (1979), against a background of rising provision of universal preschool child care, maternal employment, and generous maternity and parental leave. (Gilbert et al. 2012) One Swedish author cites the social contagion effects of information about how children should be cared for - disseminated through early day care settings, and reinforced by other parents - as responsible for the rapid adoption by immigrant families of the Swedish approach to child discipline. (Janson et al. 2010) Such methods might not work so well in a more class-segregated society, such as the UK.

Government policy initiatives since 1989 are summarised in table 1. From 1997 until the new coalition government took over in 2010, the UK government adopted elements of a public health, risk reduction approach improving child wellbeing and reducing maltreatment through investing in universal support for parents. Following Tony Blair's pledge to end child poverty three strands of policy were developed. Investment in universal child care provision, increased financial support for families, and initiatives to make work pay. As a result, child poverty was halved in absolute terms between 1999 and 2007. (Waldfogel, 2010) These policies were coupled with infrastructure targeted at deprived families with young children with services centred on Sure Start schemes based in Children's' Centres. (Waldfogel, 2010) For school age children, the children's fund, introduced in 2001, stimulated a variety of local projects that aimed to minimise the negative effects of child poverty and social exclusion. (Barnes and Morris, 2008)

Establishing whether these initiatives had a direct effect on child maltreatment is hard as measures of maltreatment experienced by children, as opposed to professional responses to child maltreatment, are not routinely collected in the UK. Better data would be provided by repeated self-report studies of maltreatment in the past year. Some evidence of a decline is provided by comparing national surveys in the UK done in 1999 and 2009. These showed some decline in harsh physical punishment or violence and in verbal aggression but not in neglect. (Radford et al. 2011) Unfortunately, these data reflect children who were ever maltreated during childhood and are strongly affected by recall of recent events by the 18 to 24 year olds surveyed. They are not good measures 
of change across all age groups. Past year data were not collected in the earlier study, but the foundation has been laid for future follow up studies to determine changes compared with the 2009 NSPCC survey. (Radford et al. 2011)

\section{Preventive healthcare}

\section{Primary care services}

Public services, particularly in health and education, can play an important role in preventing child maltreatment. Such universal services are able to take a population - wide approach to identifying and targeting high risk families. Within healthcare services, $90 \%$ of contacts take place in primary care. Primary care is the main universal service for the whole family and virtually all children are registered with a GP. Moreover, the service is run by skilled practitioners trained in fostering and maintaining therapeutic relationships with patients facing a range of health and psychosocial issues.

Knowledge of the epidemiology of child maltreatment makes clear what a pivotal role GPs could have. First, children in the UK present to primary care frequently, on average children under 5 years old consult five times a year with their GP(ONS, 2011) and about 1 in 13 children have seen their GP in the last two weeks. (Saxena et al. 2002) Second, the primary care team has insight into risk and protective factors for child maltreatment and the functioning of the family through caring for the mother and siblings, and often for the father and extended family. They are therefore well placed to monitor and respond to domestic violence, depression, drug or alcohol abuse, and signs in family members of stress, trauma or failing in parenting. Indeed, a Danish study found that half the neglected children reported by GPs were first identified through consultations for health problems in the parents. (Holge-Hazelton and Tulinius, 2010)

Third, GPs hold a continuous healthcare record for the child as well as for other family members. Hence, although patients are rarely seen by the same GP and may be seen by other members of the primary healthcare team such as a practice nurse, the record of concerns and past problems is contained in the patient's record. No other services have such longitudinal insights across multiple family members. Fourth, as child maltreatment is often a chronic condition, merging with other forms of victimisation, the primary care team can play a key role in anticipating stressors for vulnerable families and initiating support or therapeutic services. Fifth, research consistently shows that a substantial proportion of maltreated children (or members of their family) have chronic medical problems or disability. (Sullivan and Knutson, 2000) The primary care team can play a critical role in addressing health problems on an 
on-going basis. This continuity of care is particularly important for the most vulnerable families, who may spend periods of time being monitored and supported by children's social care services (e.g.: on a child protection plan), but who may nevertheless require on-going support, possibly throughout childhood, with a focus on health needs.

Although the pivotal role of the GP has been acknowledged by policymakers (Bastable 2005; Care Quality Commission 2009; Carter and Bannon 2002; Munro 2011; Royal College of General Practitioners 2004; Royal College of General Practitioners and National Society for the Prevention of Cruelty to Children 2011), in practice, there is still contention and mismatched expectations about the role and responsibilities of the GP's involvement in child protection. (Allister 2011; Fitzpatrick 2011) A second problem is that GPs' abilities proactively to pursue concerns about child maltreatment have been reduced by relocation of health visitors from GP practices into children's centres, where they work alongside social workers and early years' service providers such as Sure Start. (Gilbert et al. 2009b; Learner, 2011). In summary, the join-up between primary care and other preventive services for child maltreatment is poor.

In contrast to the UK, primary care paediatricians in the US, the equivalent of GPs in the UK with paediatric training, have a more recognised role in responding to child maltreatment and, in some areas, operating a preventive role. (Bastable, 2005; Flaherty et al. 2008; Royal College of General Practitioners and National Society for the Prevention of Cruelty to Children, 2011) Flaherty and Stirling, 2010) One approach, evaluated in a cluster randomised controlled trial - the SEEK study- involved teaching doctors about risk factors for child maltreatment, participation of a social worker in clinics, and use of a parent questionnaire to screen for substance abuse in the family, maternal depression, major stress, and intimate partner violence. (Dubowitz et al. 2011) At 2 years follow up, intervention practices showed modest but significant improvement in their targeting of family problems.

\section{Paediatric services}

The past decade has been troubled for paediatricians involved in child protection in England with the result that development of a preventive approach has been limited. Against a backdrop of disciplinary action and prosecutions of two high profile paediatricians for their conduct in child protection cases, complaints related to child protection have risen and interest in specialising in child protection has declined. (Jenny, 2007; Haines and Turton, 2008) On a more positive note, coordination of child protection has improved with establishment of named doctors and nurses for child protection and a local strategic role carried out by the designated doctor for child protection. The evidencebase has also improved, particularly on the accuracy of markers of physical or 
sexual abuse. (Kemp et al. 2008, 2009, 2010; Gilbert et al. 2009a; Maguire et al. 2009) Paradoxically, these developments have reinforced the forensic role of paediatricians and emphasised practices and documentation to support their role in judicial proceedings. (Royal College of Paediatrics and Child Health, 2006) Much less official attention has been given to their role in a preventive, public health approach to child maltreatment. However, prevention of maltreatment is seen as a core activity for UK community paediatricians, who look after children with disability or behaviour problems. In contrast US paediatricians are increasingly seen as having an important role in prevention of maltreatment. (American Academy of Pediatrics, 2001; Schor, 2003; Barth, 2009; Stagner and Lansing, 2009; Flaherty and Stirling, 2010)

Part of the reason why paediatric services have not focused on a preventive strategy to child maltreatment is the gap between evidence and practice. Emerging evidence on the epidemiology of maltreatment in the community, the chronic nature of neglect and emotional abuse, the inter-relatedness of different types of abuse and victimisation, and their links with chronic illness and disability, parental and environmental risk factors, has not been translated into services and practice.

For example, much attention has been focussed on recognition of inflicted injury. (Royal College of Paediatrics and Child Health, 2006) Yet a nationwide study of 3780 children with substantiated maltreatment in Canada found that only $4 \%$ of these children had injuries requiring medical attention. (Trocme et al. 2003) Physical and sexual abuse rarely result in clinically apparent injury and are less common than neglect and emotional abuse. Clinicians need skills in listening to children and in questioning parents and children. They also need to understand factors affecting parenting capacity and to create opportunities to observe parent-child interaction on repeated occasions. (National Collaborating Centre for Women's and Children's Health, 2009) Even in an acute paediatric unit, the majority of maltreatment concerns arise with medical admissions rather than injury admission, although these cases are often labelled as psychosocial problems rather than maltreatment (unpublished audit data, Gilbert).

The second gap is the options paediatricians have for early intervention. Action by paediatricians, or indeed by other healthcare professionals, is strongly determined by procedures laid down by the government. The scope for early intervention is largely limited to referral to children's social services or referral to Child and Adolescent Mental Health Services (CAMHS), both with high thresholds for acceptance, or liaison with the GP or with the dwindling workforce of health visitors or school nurses. Other options for therapeutic or supportive intervention, such as offering parenting training, support for drug or alcohol abuse in the parents, violence management, or interventions to improve parent-child interaction are not seen as part of the remit of an acute 
paediatric service. Very often, healthcare professionals simply cannot directly access these services except through social services.

The third gap, management of child maltreatment as a chronic condition, has has received least attention within paediatrics. Although maltreated children are frequent users of healthcare services, particularly the disproportionate number with chronic illnesses or disability, there is no official framework for on-going care or shared care with children's social care services or other providers of interventions. (Jaudes and key-Bilaver, 2008; Woodman et al. 2008, 2010) Lack of feedback from children's social services is a constant complaint from primary and secondary healthcare alike. (Gilbert et al. 2009a) Anecdotal reports suggest this has not been eased by the development of "common assessment framework" forms, which have proved lengthy and unwieldy for healthcare professionals. Contact with paediatric services initiated by children's social care services, in the form of requests for medicals, tends to be focussed on forensic input rather than wider healthcare needs, and applies to relatively few of the children seen by children's social care services.

Recent NICE guidance (The National Institute of Health and Clinical Excellence) has been an important advance in many ways. (National Collaborating Centre for Women's and Children's Health, 2009) It provided official recognition of the uncertainty faced by healthcare professionals and the fact that they frequently see children who raise concerns but do not reach the threshold for referral to children's social care services. The guidance defined 'alert features' for recognition at two levels suspect and consider. Suspected maltreatment should lead to referral to children's social care services. 'Consider' reflects a lower level of certainty. NICE guidance recommended further action for these children, including discussion with colleagues or follow up with the aim of gathering further information to decide whether to suspect or exclude maltreatment. In practice, a large number of children are likely to remain a concern but below the threshold for referral to social services. A further advance was the emphasis given to non-injury presentations of child maltreatment and the need for skills in assessing parent-child interactions. Unfortunately, the guidance did not address the question of how health professionals should intervene - apart from referral to children's social care services. While a welcome advance this guidance can have the effect of reinforcing the notion of maltreatment as a problem of "diagnosis" rather than as one of recognising children who might benefit from intervention.

\section{Children's Social Care Services}

Children's social care is responsible for both child protection and child welfare. The 1963 Children and Young Persons Act strengthened by the 1989 
Children Act included a broader welfare remit by requiring social services departments to provide services for "children in need" (figure 2 and table 1). (HM Government, 1989) Hence, an initial referral can be made to local social care services for child protection or for welfare needs, such as family dysfunction, parental illness or child disability.

In theory, the multiple remits of children's social care services should facilitate a preventive approach, with early interventions offered in response to welfare referrals, as well as a child safety approach to maltreatment. In practice, the service has largely focussed in recent years on forensic investigation and interventions to ensure child safety in response to confirmed or likely maltreatment. Part of the reason has been the lack of infrastructure and resource to implement a broader preventive remit. Another is the on-going tension between a populist, media-led focus on culpability - bringing people who harm children to justice - and a focus on improving outcomes for children. The sense of moral outrage can translate into a preoccupation, even amongst professionals, with detection and punishment rather than with interventions most likely to improve conditions for children. This tension is illustrated by the string of public inquiries into specific child deaths, which have sometimes extended the finger of culpability beyond parents to social workers and occasionally healthcare. (Laming, 2003; Care Quality Commission, 2009) Inquiries into individual deaths and national reviews of the 100 or so serious case reviews each year (death or serious injury where maltreatment was a factor) have had inordinate impact on policy, while scant attention has been paid to population-based research. However, some steps towards a more preventive, public health approach are discernible.

Major policy initiatives in the early 200os, enacted by the 2004 Children Act, explicitly reiterated the earlier preventive focus of Part 3 of the Children Act 1989 by requiring local authorities to work more closely with health services and other local agencies in order to safeguard vulnerable children, meaning intervening to prevent maltreatment or victimisation (figure 2, table 1). (Department of Health and Department for Education and Skills, 2001;

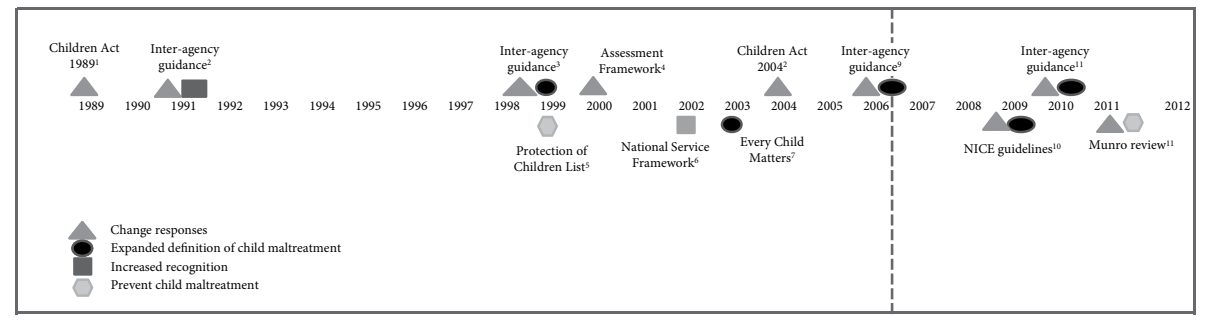

Figure 2 Children's social care policy timeline. 
Department for Education and Skills, 2003, 2006; HM Government, 2004) Safeguarding includes promoting the welfare of children in need - defined by the 1989 Children Act as those whose vulnerability is such that they are unlikely to reach or maintain a satisfactory level of health or development or their health or development will be significantly impaired, without the provision of services. (Department of Health \& Department for Education and Skills, 2001; Department for Education and Skills, 2003; HM Government, 2004) Safeguarding is a way of targeting the high risk population, as shown in figure 1, who might benefit from targeted interventions.

One source of confusion about safeguarding is the stated aim to prevent maltreatment happening in the first place. This ignores evidence on the chronic nature of child maltreatment and the fact that professionals outside children's social care services are managing, on a daily basis, 'marginally maltreated' children who are already being maltreated, but who do not reach the threshold for referral to social care services. Because, of limited resources, children at risk of significant harm who require formal child protection investigation are prioritised for assessment and services. This system encourages professionals to label children as needing child protection services, which can be intrusive and punitive, less cost effective and less likely to encourage parental engagement than welfare support for a child in need.

A second problem is the lack of guidance about where the line of intervention should be drawn in the distribution of parenting shown in figure 1. The definition of "child in need" requires an assessment of the child's likelihood of benefitting from intervention. This in turn requires information on the risks of failure to develop or thrive in the long term without intervention and the likely effectiveness of the intervention for improving these outcomes. The prognostic and intervention studies required to inform these assessments are not currently available, leaving decisions about who should be targeted to be based on professional judgement and availability of resources, with inevitable variation between local authorities in thresholds for action.

Nationally, the preventive, 'safeguard and promote welfare' remit of children's social care services has not had a marked impact on service activity. Referrals to children's social care services have not climbed steeply, as happened in New Zealand, where broadening of eligibility for welfare interventions and easier reporting methods led to a four-fold increase in notifications and a doubling in the number of investigations. (Mansell, 2007) In England, referrals increased only slightly from $4.9 \%$ of all children each year in 2002 to $5.6 \%$ in 2010 , and the proportion of children placed on a child protection plan has remained around 0.3 to $0.4 \%$ of all children each year. (Department for Education, 2002, 2011)

The development of child protection policy over the last decade has been analysed in a detailed and critical review by Munro. (Munro, 2011) The review 
reiterated the importance of a preventive, proactive approach, targeted at vulnerable families. The report focussed on social care and how the child protection system could be improved through better understanding of the inherent uncertainty and risk in child protection, the need for professional judgement, and the importance of considering the effectiveness of interventions when responding to child maltreatment. The review also recognised the heterogeneity of child maltreatment and the fact that varied responses are needed. One solution proposed was more scope for localism and innovation, an approach likely to fit well with government strategy to open up public services to a range of providers. Expanding the research base was mentioned but insufficiently emphasised. There was no vision of investment in robust research for children's social care, similar to the NIHR investment in applied research for health, and recently for adult social care, to inform practice across the NHS and social care.

The review did recognise the importance of other public services, schools, primary care and adult mental health services were mentioned specifically to aid social care in their proactive, preventive approach. Details were lacking however, about how other public services could intervene early in response to concerns about child maltreatment, when the threshold for child protection investigations has not been reached.

\section{Future directions}

The research evidence favours a shift towards a public health, preventive approach to child maltreatment, away from a forensic approach focussed on immediate safety and culpability. Lessons from epidemiology suggest that prevention involving universal support for families has the potential to have greatest impact, by shifting the curve towards support for effective parenting. (Harper, 2009) Unfortunately, the progress seen towards universal support for families in the last ten years seems unlikely to continue in the present political climate. (Waldfogel, 2010) However, the drive towards preventive action for high risk families is strongly supported by the coalition government, (Field, 2010; Allen, 2011) although the role for healthcare in this approach has not yet been clearly delineated.

Two areas need urgent development in the future. First, a greater focus on services for parents as a way of preventing, recognising and responding to child maltreatment. Evidence of such activity is starting to emerge with official recognition of the potential role of adult mental health services, (Munro, 2011) and trials involving early intervention by clinicians to address parental problems in order to reduce maltreatment. (MacMillan et al. 2009b; Dubowitz et al. 
2011) Inclusion of GPs in this vision for early intervention needs to be expanded and evaluated in the UK. Proactive, preventive roles for GPs and paediatricians, particularly where child maltreatment is a chronic condition, will require access to social welfare interventions outside the direction of children's social care services.

The second area for development is the research agenda. Unless we can provide evidence of effectiveness of preventive interventions on a population basis the focus is likely to remain on culpability and children's immediate safety where interventions are coercive and sanctioned by law. Early interventions potentially affect many more families, they usually depend on voluntary participation, and they need to be acceptable and helpful. They also need to show benefits outweighing harms, using valid measures of child wellbeing. The same logic needs to be applied to coercive interventions, particularly where early intervention and coercion converges - in the early removal of very young children from their parents - now more common in England than most other western developed countries. (Department for Education, 2011b)

As the research base develops, the heterogeneity of child maltreatment and need for diverse intervention strategies is likely to become more apparent. We need to recognise how thin is the evidence base to support the drastic ways we intervene in children's lives and invest to find out what works, when and for whom.

\section{References}

Allen, G., Early Intervention: The Next Steps. An Independent Report to her Majesty's Government (London, UK: HM Government, 2011).

Allister, J. 2011. How to protect general practice from child protection. British Journal of General Practice, 61, (586) 326.

American Academy of Pediatrics, 'The Pediatrician's role in family support programs. Committee on early childhood and adoption, and dependent care', Pediatrics 107(1) (2001): 195-197.

Andrews, G., Corry, J., Slade, T. et al., 'Child sexual abuse'. In Comparative Quantification of Health Risks (Geneva: World Health Organization, 2004).

Barlow, J. \& Calam, R., 'A public health approach to safeguarding in the 21st century', Child Abuse Review 20 (2011): 238-255.

Barnes, M. \& Morris, K., 'Strategies for the prevention of social exclusion: An analysis of the Children's fund', Journal of Social Policy 37(2) (2008): 251-270.

Barth, R.P., 'Preventing child abuse and neglect with parent training: Evidence and opportunities', The Future of Children 19(2) (2009): 95-118.

Bastable, R., Keep Me Safe: The RCGP Strategy for Child Protection (London RCGP, 2005).

Care Quality Commission, Review of the Involvement and Action Taken by Health Bodies in Relation to the Case of Baby P. Care Quality Commission (London: London, Care Quality Commission, 2009).

Carter, Y. \& Bannon, M., The role of primary care in the protection of children from abuse and neglect: A Position Paper for the Royal College of General Practitioners (London: Royal College of General Practitioners, 2002). 
Department for Education. Referrals, assessments and children who were the subject of a childprotection plan (2010-11 Children in Need census, Provisional). http://www.education.gov .uk/rsgateway/DB/STR/doo1025/index.shtml 2011.

Department for Education, Referrals, Assessments and Children and Young People on Child Protection Registers Year Ending 31 March 2002 (London, UK: Department for Education, 2002).

Department for Education. Referrals, assessments and children who were the subject of a child protection plan (2010-11 Children in Need census, Provisional). http://www.education.gov .uk/rsgateway/DB/STR/doo1025/index.shtml. Department for Education, 2011a (last accessed 27.03.12).

Department for Education. Children Looked After by Local Authorities in England (including adoption and care leavers) - year ending 31st march 2011: Statistical first release. http://www .education.gov.uk/researchandstatistics/datasets/aoo196857/children-looked-after-by-las -in-england. (last accessed 27.03.12). Department for Education, 2011b.

Department for Education, Working Together: An Interagency Guide to Safegaurding and Promoting the Welfare of Children (London: Department for Education, 2010).

Department for Education and Skills, Every Child Matters: Change for Children (London: The Stationery Office, 2003). http://www.dcsf.gov.uk/everychildmatters/publications/ outcomescyp/(last accessed 15.03.10).

Department for Education and Skills, 'Chapter 8' of Working Together to Safeguard Children: A Guide to Inter-agency Working to Safeguard and Promote the Welfare of Children (London: HMSO, 2006).

Department of Health \& Department for Education and Skills, National Service Framework for Children, Young People and Maternity Services (London: Department of Health, 2001).

Dubowitz, H., Lane, W.G., Semiatin, J.N. et al., 'The safe environment for every kid model: Impact on pediatric primary care professionals', Pediatrics 127(4) (2011): eg62-e97o.

Field, F., The Foundation Years: Preventing Poor Children Becoming Poor Adults. The Report of the Independent Review on Poverty and Life Chances (London: HM Government, 2010).

Finkelhor, D., Turner, H., Ormrod, R. et al., 'Violence, abuse, and crime exposure in a national sample of children and youth'. Pediatrics 124(5) (2009): 1411-1423.

Finkelhor, D., Turner, H., Ormrod, R. et al., 'Trends in childhood violence and abuse exposure: Evidence from 2 national surveys'. Archives of Pediatrics \& Adolescent Medicine 164(3) (2010): 238-242.

Fitzpatrick, M. 2011. How to protect general practice from child protection. British Journal of General Practice, 61, (585) 299.

Flaherty, E.G., Sege, R.D., Griffith, J. et al., 'From suspicion of physical child abuse to reporting: Primary care clinician decision-making', Pediatrics 122(3) (2008): 611-619.

Flaherty, E.G. \& StirlingJ. Jr., 'Clinical report-the pediatrician's role in child maltreatment prevention', Pediatrics 126(4) (2010): 833-841.

Gilbert, R., Kemp, A., Thoburn, J. et al., 'Recognising and responding to child maltreatment', Lancet 373(9658) (2009a): 167-180.

Gilbert, R., Widom, C.S., Browne, K. et al., 'Burden and consequences of child maltreatment in high-income countries', Lancet 373(9657) (2009b): 68-81.

Gilbert, R., Fluke, J., O’Donnell, M., Gonzalez-Izquierdo, A., Brownell, M., Gulliver, P., Janson, S., \& Sidebotham, P. Child maltreatment: variation in trends and policies in six developed countries. Lancet, 379, (9817) 2012: 758-772.

Gray, J., World Perspectives on Child Abuse (Colorado, USA: ISPCAN, 2010, Ninth edition).

Haines, L. \& Turton, J., 'Complaints in child protection', Archives of Disease in Childhood 93(1) (2008): 4-6.

Harper, S., 'Rose's strategy of preventive medicine.Geoffrey Rose with commentary by Kay-Tee Khaw and Michael Marmot', International Journal of Epidemiology 38(6) (2009): 1743-1745.

HM Government, Children Act 1989 (London: HMSO, 1989).

HM Government, Children Act 2004 (London: HMSO, 2004). 
Holge-Hazelton, B. \& Tulinius, C., 'Beyond the specific child. What is 'a child's case' in general practice?', British Journal of General Practice 6o(570) (2010): e4-eg.

Janson, S., Langberg, B. \& Svensson, B., 'Sweden. A 30 year ban on the physical punishment of children'. In Global Pathways to Abolishing Physical Punishment. Realizing Children's Rights. eds. J.E. Durrant \& A. Smith (London: Routledge, 2010) 241-255.

Jaudes, P.K. \& key-Bilaver, L., 'Do chronic conditions increase young children's risk of being maltreated?', Child Abuse \& Neglect 32(7) (2008): 671-681.

Jenny, C., 'The intimidation of British pediatricians', Pediatrics 119(4) (2007): 797-799.

Kemp, A.M., Dunstan, F.D., Harrison, S. et al., 'Patterns of skeletal fractures in child abuse: Systematic review', BMJ 337 (2008): a1518.

Kemp, A.M., Joshi, A.H., Mann, M. et al., 'What are the clinical and radiological characteristics of spinal injuries from physical abuse: A systematic review', Archives of Disease in Childhood 95(5) (2010): $355^{-360 .}$

Kemp, A.M., Rajaram, S., Mann, M. et al., 'What neuroimaging should be performed in children in whom inflicted brain injury (iBI) is suspected? A systematic review', Clinical Radiology 64(5) (2009): 473-483.

Laming, L., The Victoria Climbie Inquiry: Report of an Inquiry (London: Crown Copyright, 2003). http://www.victoria-climbie-inquiry.org.uk/finreport/finreport.htm (last accessed 15.03.10)

Learner, S., 'After baby P: Can GPs follow child protection guidance?', BMJ 342 (2011): d707.

Leeb, R.T., Paulozzzi, L., Melanson, C. et al., Child Maltreatment Surveillance. Uniform Definitions for Public Health and Recommended Data Elements (Atlanta, Georgia: Centers for Disease Control and Prevention, 2008).

MacMillan, H.L., Wathen, C.N., Barlow, J. et al., 'Interventions to prevent child maltreatment and associated impairment', The Lancet 373(9659) (2009a): 250-266.

MacMillan, H.L., Wathen, C.N., Jamieson, E. et al., 'Screening for intimate partner violence in health care settings: A randomized trial', JAMA 302(5) (2009b): 493-501.

Maguire, S., Pickerd, N., Farewell, D. et al., 'Which clinical features distinguish inflicted from non-inflicted brain injury? A systematic review', Archives of Disease in Childhood 94(11) (2009): 860-867.

Mansell, J., 'The underlying instability in statutory child protection: Understanding the system dynamics driving risk assurance levels', Social Policy Journal of New Zealand 18 (2007): 97-132.

Munro, E., The Munro Review of Child Protection: Final Report - A Child-Centred System (Department for Education, 2011).

National Collaborating Centre for Women's and Children's Health, When to Suspect Child Maltreatment (London: National Institute for Health and Clinical Excellence, 2009).

O'Donnell, M., Scott, D. \& Stanley, F., 'Child abuse and neglect - is it time for a public health approach?', Australian and New Zealand Journal of Public Health 32(4) (2008): 325-330.

ONS, NHS general medical practitioner consultations: by age, 2000/o1: Social Trends 33. 2011.

Radford, L., Corral, S., Bradley, C. et al., Maltreatment and Victimisation of Children and Young People in the UK (London: NSPCC, 2011).

Reading, R., Bissell, S., Goldhagen, J. et al., 'Promotion of children's rights and prevention of child maltreatment', The Lancet 373(966o) (2009): 332-343.

Rees, G., Gorin, S., Jobe, A. et al., Safeguarding Young People: Responding to Young People Aged 11-17 Who are Maltreated (London: NSPCC, 2010).

Rose, G., Khaw, K.-T. \& Marmot, M., Rose's Strategy of Preventive Medicine (Revised edition ed. Oxford, UK: Oxford University Press, 2008).

Royal College of General Practitioners Grasping the Nettle: Information Sharing and the Child, (London: RCGP, 2004).

Royal College of General Practitioners (RCGP) \& National Society for the Prevention of Cruelty to Children (NSPCC), Safeguarding Children and Young People in General Practice: A Toolkit (London: RCGP and NSPCC, 2011).

Royal College of Paediatrics and Child Health, Child Protection Companion (London: Royal College of Paediatrics and Child Health, 2006). 
Runyan, D.K., Shankar, V., Hassan, F. et al., 'International variations in harsh child discipline', Pediatrics 126(3) (2010): e701-e711.

Runyan, D.K. \& Zolotor, A.J., International Issues in Child Maltreatment, 3rd ed. C. Jenny, ed., (Thousand Oaks, California: Sage Publications, 2011) 617-624.

Saxena, S., Eliahoo, J. \& Majeed, A., 'Socioeconomic and ethnic group differences in self reported health status and use of health services by children and young people in England: Cross sectional study', British Medical Journal 325(7363) (2002): $5^{20}$.

Schor, E.L., 'Family pediatrics: Report of the task force on the family', Pediatrics 111(6 Pt 2) (2003): 1541-1571.

Sebre, S., Sprugevica, I., Novotni, A. et al., 'Cross-cultural comparisons of child-reported emotional and physical abuse: Rates, risk factors and psychosocial symptoms', Child Abuse \& Neglect 28(1) (2004): 113-127.

Sidebotham, P., 'An ecological approach to child abuse: Creative use of scientific models in research and practice', Child Abuse Review 10 (2001): 97-112.

Stagner, M.W. \& Lansing, J., 'Progress toward a prevention perspective', The Future of Children 19(2) (2009): 19-38.

Sullivan, P.M. \& Knutson, J.F., 'Maltreatment and disabilities: A population-based epidemiological study', Child Abuse \& Neglect 24 (2000): 1257-1273.

Trocme, N., MacMillan, H., Fallon, B. et al., 'Nature and severity of physical harm caused by child abuse and neglect: Results from the Canadian Incidence Study', Canadian Medical Association Journal 169(9) (2003): 911-915 available from: http://www.cmaj.ca/cgi/content/ abstract $/ 169 / 9 / 911$

Turner, H.A., Finkelhor, D. \& Ormrod, R., 'Poly-victimization in a national sample of children and youth', American Journal of Preventive Medicine 38(3) (2010a): 323-330.

Turner, H.A., Finkelhor, D. \& Ormrod, R., 'The effects of adolescent victimization on self -concept and depressive symptoms', Child Maltreatment 15(1) (2010b): 76-90.

Unicef, Child Disciplinary Practices at Home: Evidence from a Range of Low and Middle Income Countries (New York, USA: UNICEF, 2010).

Violence Prevention Alliance, The Public Health Approach (2011). http://www.who.int /violenceprevention/approach/public_health/en/index.html

Waldfogel, J., Britain's War on Poverty (London: Russell Sage Foundation, 2010).

Woodman, J., Brandon, M., Bailey, S., Belderson, P., Sidebotham, P., \& Gilbert, R. 2011. Healthcare use by children fatally or seriously harmed by child maltreatment: analysis of a national case series 2005-2007. Archives of Disease in Childhood, 96, (3) 270-275.

Woodman, J., Pitt, M., Wentz, R. et al., 'Performance of screening tests for child physical abuse in accident and emergency departments', Health Technol Assess 12(33) (2008): iii, xi-xiii, 1-95

Zolotor, A.J., Runyan, D.K., Dunne, M.P. et al., 'ISPCAN Child Abuse Screening Tool Children's Version (ICAST-C): Instrument development and multi-national pilot testing', Child Abuse \& Neglect 33(11) (2009): 833-841. 